\title{
Carbide Nanoparticles Encapsulated in the Caves of Carbon Nanotubes by an In Situ Reduction-Carbonization Route
}

\author{
Chunli Guo, ${ }^{1}$ Yitai Qian, ${ }^{2}$ and Pengju Han ${ }^{3}$ \\ ${ }^{1}$ College of Materials Science and Engineering, Taiyuan University of Technology, Taiyuan 030024, China \\ ${ }^{2}$ Key Laboratory of Colloid and Interface Chemistry, Shandong University, Ministry of Education, Jinan 250100, China \\ ${ }^{3}$ College of Architecture and Civil Engineering, Taiyuan University of Technology, Taiyuan 030024, China
}

Correspondence should be addressed to Chunli Guo, gcl@sdu.edu.cn

Received 11 July 2011; Revised 23 September 2011; Accepted 26 September 2011

Academic Editor: Renzhi Ma

Copyright ( $) 2011$ Chunli Guo et al. This is an open access article distributed under the Creative Commons Attribution License, which permits unrestricted use, distribution, and reproduction in any medium, provided the original work is properly cited.

\begin{abstract}
Carbides (TiC, WC, and NbC) nanoparticles fully encapsulated in the caves of carbon nanotubes (CNTs) were synthesized via an in situ reduction-carbonization route at $600^{\circ} \mathrm{C}$ in an autoclave. The structural features and morphologies of as-obtained products were investigated using by X-ray diffraction, scanning electron microscopy, and high-resolution transmission electron microscopy (HRTEM). HRTEM studies showed that the average diameter of CNTs encapsulated with carbide nanoparticles are in the range of $15-40 \mathrm{~nm}$. The reaction temperature, the reaction time, and the metal catalyst are found to play crucial roles to the product morphology. The growth mechanism of carbide nanoparticles encapsulated in CNTs was discussed in detail.
\end{abstract}

\section{Introduction}

Transition metal carbides are important materials because they possess some desired properties such as thermal stability, corrosion, and wear resistance, electronic, magnetic, and catalytic characteristics [1-4]. Among them, titanium carbide (TiC), tungsten carbide (WC), and niobium carbide $(\mathrm{NbC})$ are three kinds of important transition metal carbides, which are applied as cutting tools, ceramics, and wearresistance materials [5-7]. Furthermore, WC shows excellent catalyst properties similar to platinum [8]. However, their widespread applications have been limited due to their inherent brittleness, catastrophic failure mode, and gathering [9]. Carbon nanotubes (CNTs) highlighted by the work of Iijima [10] in 1991 are now a major component of nanotechnology, which have attracted increasing attention because of their unusual properties and numerous potential applications [11]. The encapsulation of these carbides in CNTs has also attracted widespread attention, not only because CNTs can be used as protecting shells to environmental effects, but also because they exhibit more excellent properties than individual materials such as magnetic, catalytic, electronic, and optical properties [12-15]. The reported encapsulation phases inside CNTs were mainly metals and oxides but scarcely carbides. The encapsulation of carbides nanoparticles in CNTs can compensate for the defect of each other and make better. For transition metal carbides, it can increase their specific surface area and decrease their aggregation. Simultaneously, the CNTs properties such as field emission properties, electrical conductivity, and quantum transport behavior can be improved better. All these will extremely enlarge their applications compared to single material.

To date, some synthetic methods about TiC, WC, and $\mathrm{NbC}$ nanoparticles encapsulated in CNTs systems have been investigated. Pan et al. [16] reported TiC nanoparticles coated with CNTs prepared by CVD had good field emission properties. WC-CNTs composites were synthesized by the reduction and carbonization process [17] and the shape memory synthesis method [18]. NbC nanoparticles encapsulated in CNTs were produced by arcing electrodes of graphite-metal mixtures, and its susceptibility property was also studied [19]. Most reports described that carbides located either on the inner surface or on the outer surface of CNTs to form composite materials. However, to our knowledge, there 
have been few reports about TiC, WC, and NbC nanoparticles fully encapsulated in the caves of CNTs up to now.

Pyrolysis of ferrocene has been proved to be the most promising way to prepare not only CNTs but also carbonencapsulated ferromagnetic nanoparticles [20-22]. Distinct from other approaches, ferrocene can supply both iron as catalyst of CNTs growth and carbon sources in the synthetic strategy. Therefore, we present a way to fabricate TiC, WC, and $\mathrm{NbC}$ nanoparticles fully encapsulated in CNT caves by an in-situ reduction-carbonization route at $600^{\circ} \mathrm{C}$ in an autoclave, and the growth mechanisms of as-obtained samples were discussed in detail.

\section{Experimental Section}

TiC, WC, and NbC nanoparticles encapsulated in the CNT caves were prepared as follows. In a typical experimental procedure, $2 \mathrm{~g}$ ferrocene, $1 \mathrm{~g}$ metal oxide $\left(\mathrm{TiO}_{2}, \mathrm{WO}_{3}\right.$, or $\mathrm{Nb}_{2} \mathrm{O}_{5}$ ), and $1 \mathrm{~g} \mathrm{Mg}$ powder were mixed and placed in a $50 \mathrm{~mL}$ stainless-steel autoclave. The autoclave was sealed and put into an electronic furnace which was heated to $600^{\circ} \mathrm{C}$ for $10 \mathrm{~h}$, then cooled to room temperature in the air. The black powder products were collected and washed with distilled water, dilute $\mathrm{HCl}$, and absolute ethanol in turn several times. Finally, the products were dried under vacuum at $50^{\circ} \mathrm{C}$ for $6 \mathrm{~h}$. In addition, the final products of WC-CNTs were treated with ammonia to remove $\mathrm{W}_{2} \mathrm{C}$ impurities.

$\mathrm{X}$-ray powder diffraction (XRD) measurements were carried out using a Bruker D8 advanced X-ray diffractometer equipped with graphite monochromatized $\mathrm{Cu} \mathrm{K} \alpha$ radiation $(\lambda=1.5418 \AA)$. Field emission scanning electron microscopy (FESEM) images were taken by a JSM-6700F scanning electron microscope. The transmission electron microscopy (TEM) images were obtained by a Hitachi model H-7000 TEM. The high-resolution (HRTEM) images were recorded on a JEOL 2100 transmission electron microscope.

\section{Results and Discussion}

The XRD pattern of as-obtained samples is shown in Figure 1 , which confirms that the three samples were composed of two phases: the broad peaks with relatively low peak intensity could be ascribed to the diffraction of graphite (marked with "o"); the other sharp peaks with relatively high peak intensity could be indexed as carbides. From Figure 1(a), the sharp and high-intensity diffraction peaks can be indexed to face-centered cubic TiC (JCPDS card no. 65-8417). The XRD pattern of Sample 2 is shown in Figure 1(b), which reveals that the diffraction peaks are indexed as hexagonal WC (JCPDS card no. 65-4539). Figure 1(c) shows the typical XRD pattern of Sample 3, which can be indexed as facecentered cubic NbC (JCPDS card no. 65-8784). The CNTrelated graphite peaks are detected at $22.6^{\circ}$ and $44.9^{\circ}$ for the graphite (002) and (102) planes, respectively.

Figure 2(a) is HRTEM image of Sample 1, which shows that $\mathrm{TiC}$ nanoparticles are encapsulated in CNTs with a diameter range of $15-25 \mathrm{~nm}$ at some intervals. The inset of Figure 2(a) is a single CNT encapsulated with some TiC nanoparticles. It is clear that the CNT is not one-dimen-

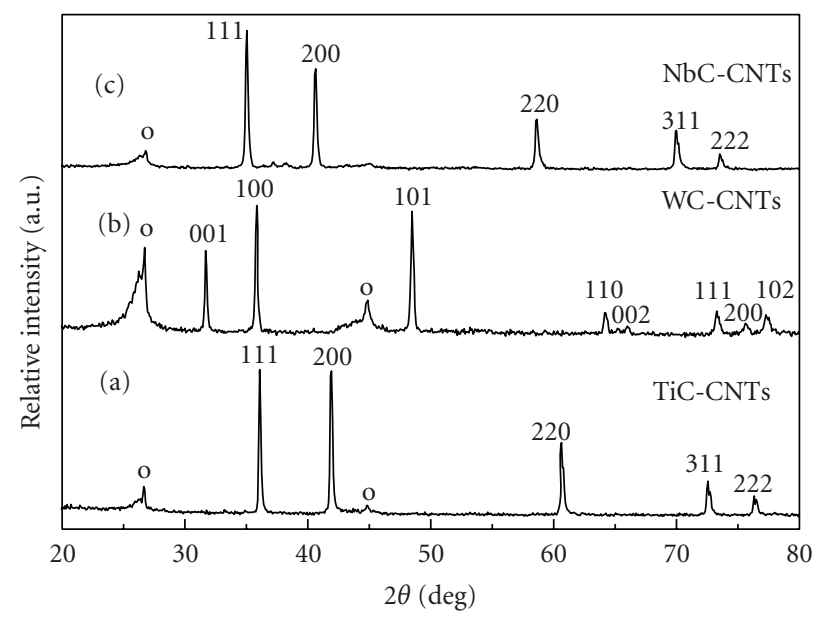

o C

FIGURE 1: XRD patterns of the as-obtained samples: (a) TiC-CNTs, (b) WC-CNTs, and (c) NbC-CNTs.

sion smooth, but bamboo-like and $\mathrm{TiC}$ nanoparticles are encapsulated in small caves of bamboo-like CNTs, which are different from previous reports that $\mathrm{TiC}$ nanoparticles were located on the surface of CNTs. Detailed structural analysis of the core-sheath nanostructures was carried out with HRTEM (shown in Figure 2(b)). The HRTEM image of the core indicates clearly resolved interplanar distances of $0.201 \mathrm{~nm}$, corresponding to the (200) lattice spacing of TiC. In addition, it can be seen that there is a layered structure which the d-spacing of $0.32 \mathrm{~nm}$ corresponds well to the (200) lattice spacing of graphite. In contrast, with well-crystallized graphite layers in CNTs, there are many staking faults in the bamboo-like carbon wall. There are some TiC nanoparticles outside of CNTs. Those sizes are larger than that of inside CNTs possibly due to their easy aggregation property. Figure 2(c) shows the HRTEM images of Sample 2. Sample 2 is also consisted of nanoparticles and CNT with a diameter range of 20-40 nm, and nanoparticles lie on the inner channels of the CNT. The inset SEM image shows that a knot in the middle of the CNT suggests that the WC nanoparticle is wrapped in graphite. The crystal plane distances of the nanoparticle inside the cave of CNT is $0.188 \mathrm{~nm}$ (shown in Figure 2(d)), which is almost equal to that of WC (101) plane. Figure 2(e) shows the typical HRTEM image of Sample 3, which indicates that Sample 3 is mainly composed of nanotubes with a diameter range of 30-40 $\mathrm{nm}$ and lengths up to ten micrometers. In addition, a few nanoparticles were located on the outside surface of the CNT. The inset of Figure 2(e) is a SEM image of a closed CNT tumid end, implying that the $\mathrm{NbC}$ nanoparticles were encapsulated in the CNTs. HRTEM image (shown in Figure 2(f)) indicates that the d-spacing of $0.157 \mathrm{~nm}$ corresponds well to the (220) lattice spacing of $\mathrm{NbC}$, and the fringe interplanar spacing was close to those of graphite.

In order to explain the growth mechanism, a series of controlled experiments were carried out. The experimental 


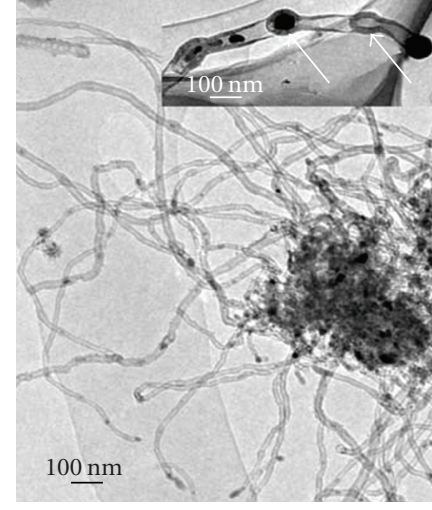

(a)

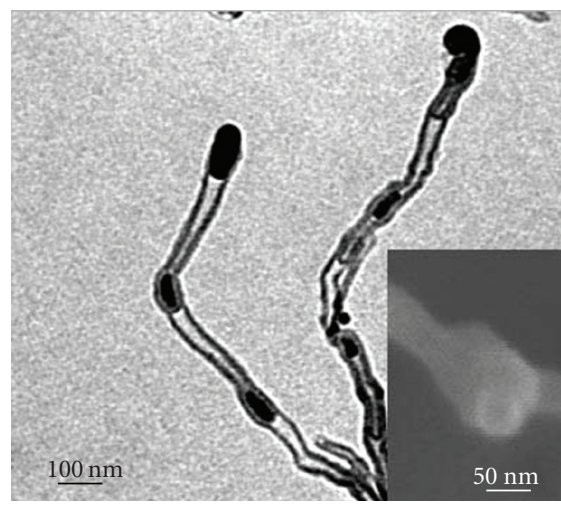

(c)

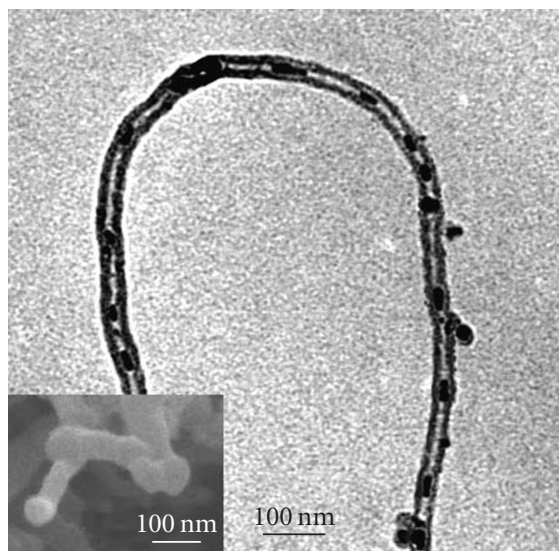

(e)

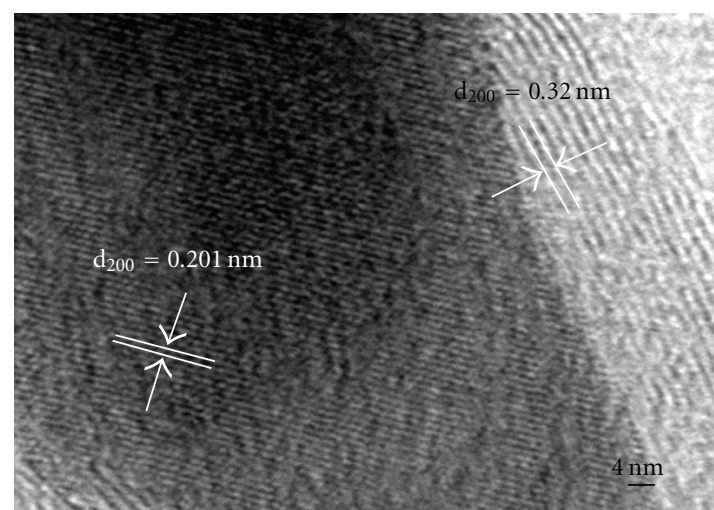

(b)

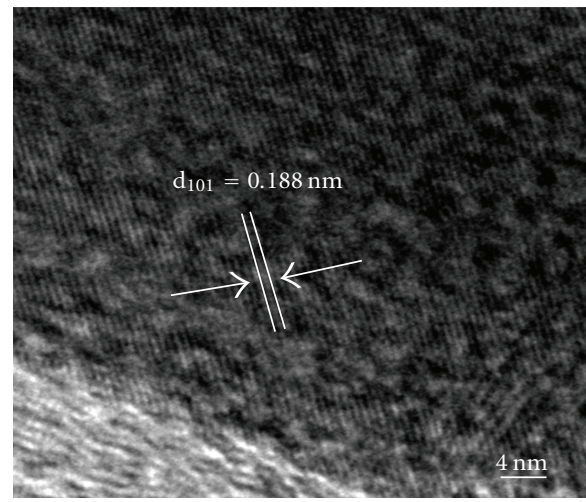

(d)

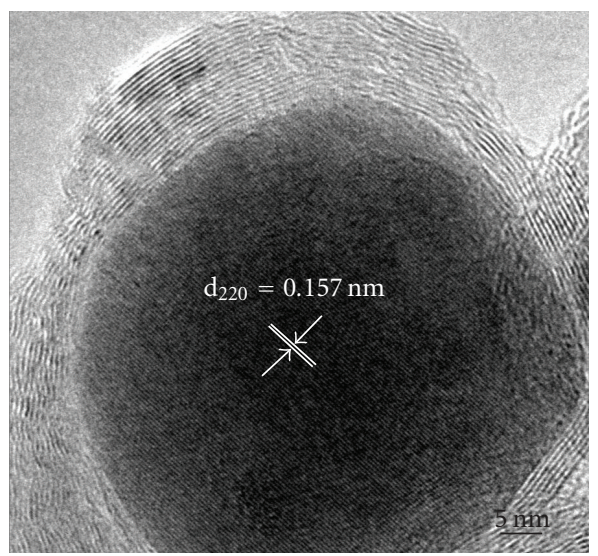

(f)

Figure 2: Typical HRTEM and SEM images of the as-obtained samples: (a,b) TiC-CNTs, (c,d) WC-CNTs, and (e,f) NbC-CNTs.

results proved that $\mathrm{Mg}$ powder played a key role in the formation of CNTs. When heating pure ferrocene or the mixture of ferrocene and $\mathrm{TiO}_{2}$, the morphologies of the final products are symmetrical spiral carbon nanofibers (Figure 3(a)) and oxhorn-like (Figure 3(b)). Leonhardt et al. obtained carbon nanotubes when heating pure ferrocene [14], which is different from our results. The possible reason of forming symmetrical spiral carbon nanofibers was that the magnetic $\mathrm{Fe}$ particles (arrowed in Figure 3(c)) were attracted mutually to cause two sections of textile fibers to curve and approach in the sealed system. As adding Mg powder to pure ferrocene, straightforward CNTs instead of flexural carbon nanofibers were obtained in the final products. The catalyst particle located in the top of both the CNTs (Figure 3(d)) was observed in the untreated samples, which were used as the catalyst to promote the 1-D carbon nanomaterials formation corresponding to vapor-liquid-solid growth mechanism [23]. Moreover, the amount of $\mathrm{Mg}$ powder also has a great influence on the formation of CNTs. As the amount of $\mathrm{Mg}$ powders is less than $0.1 \mathrm{~g}$, only carbon nanofibers can be found in the final products. If increasing it to $0.3 \mathrm{~g}$, carbon nanofibers and CNTs along with a small quantity of carbon 


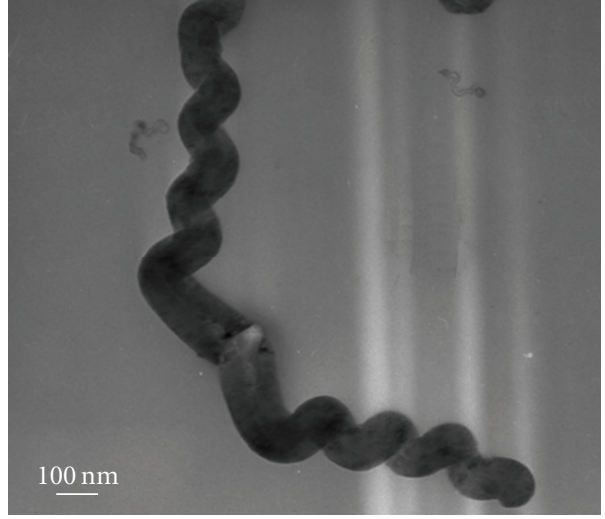

(a)

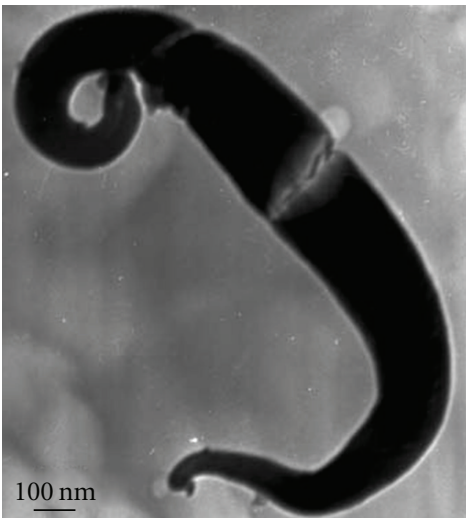

(b)

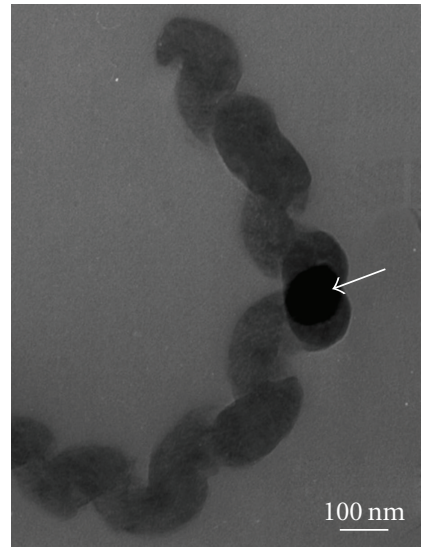

(c)

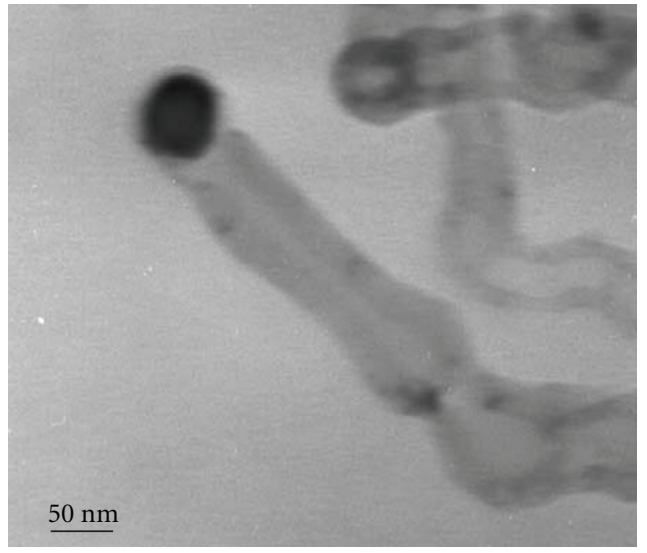

(d)

FIGURE 3: Typical HRTEM images showing the reaction progress. (a) Heated ferrocene, (b) heated mixture of ferrocene and $\mathrm{TiO}_{2}$, and (c,d) metal particles located on the 1-D carbon nanomaterials.

hollow spheres coexisted in the sample. Only above $0.5 \mathrm{~g}$, the final products were the straight CNTs entirely. In the route of carbides encapsulated in CNTs, Mg powder was used both as catalyst to CNTs formation and as reducing agent. Carbon particles deposited on the surface of the fresh $\mathrm{Ti}$ obtained from the reaction between $\mathrm{TiO}_{2}$ and $\mathrm{Mg}$ at $600^{\circ} \mathrm{C}$ to form carbides, which were wrapped up by excessive carbon to form the encapsulation subsequently.

In addition, the effect of reaction temperature, reaction time, different oxides, and metal reducing agents on the final formation of carbides encapsulated in CNTs was also investigated. Only CNTs were produced if reaction temperature was lower than $600^{\circ} \mathrm{C}$. The experimental data also indicated that the reaction would be incomplete if reaction time was shorter than $2 \mathrm{~h}$. As the reaction time prolonged, the amount of carbides nanoparticles encapsulated in CNTs increased. It is found that no carbides formed if oxides were substituted by $\mathrm{SiO}_{2}$ or $\mathrm{B}_{2} \mathrm{O}_{3}$. The possible reason was that the reaction between $\mathrm{SiO}_{2}$ or $\mathrm{B}_{2} \mathrm{O}_{3}$ and $\mathrm{Mg}$ needed higher temperature. As other metals such as $\mathrm{Na}, \mathrm{Zn}, \mathrm{Ca}, \mathrm{Fe}, \mathrm{Ni}, \mathrm{Co}$, and $\mathrm{Cr}$ were substituted for $\mathrm{Mg}$ powder, there were no carbides existing in the final products. If the oxides $\left(\mathrm{TiO}_{2}\right.$ and $\left.\mathrm{WO}_{3}\right)$ were replaced with the corresponding metals, there were also no carbides because the activity of the fresh $\mathrm{Ti}$ or $\mathrm{W}$ was lower than the commercial products.

\section{Conclusions}

In summary, $\mathrm{TiC}, \mathrm{WC}$, and $\mathrm{NbC}$ nanoparticles fully encapsulated in the caves of CNTs have been prepared via in situ reduction carbonization at $600^{\circ} \mathrm{C}$ in an autoclave. HRTEM studies show that $\mathrm{TiC}$, WC, or NbC nanoparticles are located in the caves of CNTs, and a spot of carbides particles exists outside of CNTs. The average diameters of the prepared CNTs are in the range of $15-40 \mathrm{~nm}$. The reaction temperature, the reaction time, and the metal catalyst are key influencing factors to the product morphology. The growth mechanism of carbides encapsulated in CNTs was discussed in detail.

\section{Acknowledgments}

Financial support from the National Natural Science Foundation of China (no. 20671058) and the Talent Introduction Funding of Taiyuan University of Technology are greatly 
appreciated. The authors thank Dr. Pamela Holt for editing the manuscript for English.

\section{References}

[1] C. C. Yu, S. Ramanathan, B. Dhandapani, J. G. Chen, and O. S. Ted, "Bimetallic Nb-Mo carbide hydroprocessing catalysts: synthesis, characterization, and activity studies," The Journal of Physical Chemistry B, vol. 101, no. 4, pp. 512-518, 1997.

[2] D. R. Sadoway, "Electrochemical processing of refractory metals," Journal of the Minerals Metals \& Materials Society, vol. 47, no. 7, pp. 15-19, 1991.

[3] S. Niu and M. B. Hall, "Theoretical studies on reactions of transition-metal complexes," Chemical Reviews, vol. 100, no. 2, pp. 353-406, 2000.

[4] M. M. Rohmer, M. Bénard, and J. M. Poblet, "Structure, reactivity, and growth pathways of metallocarbohedrenes $\mathrm{M}_{8} \mathrm{C}_{12}$ and transition metal/carbon clusters and nanocrystals: a challenge to computational chemistry," Chemical Reviews, vol. 100, no. 2, pp. 495-542, 2000.

[5] Y. Liang and S. P. Dutta, "Application trend in advanced ceramic technologies," Technovation, vol. 21, no. 1, pp. 61-65, 2001.

[6] S. H. Jhi, S. G. Louie, M. L. Cohen, and J. Ihm, "Vacancy hardening and softening in transition metal carbides and nitrides," Physical Review Letters, vol. 86, no. 15, pp. 33483351, 2001.

[7] B. F. Dal, S. G. Hardin, D. G. Hay, and T. W. Turney, "Selective, low-temperature synthesis of niobium carbide and a mixed (niobium/tungsten) carbide from metal oxide-polyacrylonitrile composites by carbothermal reduction," Journal of Materials Science, vol. 28, no. 24, pp. 6657-6664, 1993.

[8] F. H. Ribeiro, R. A. Dalla Betta, M. Boudart, J. Baumgartner, and E. Iglesia, "Reactions of neopentane, methylcyclohexane, and 3 3-dimethylpentane on tungsten carbides: the effect of surface oxygen on reaction pathways," Journal of Catalysis, vol. 130, no. 1, pp. 86-105, 1991.

[9] A. Biedunkiewicz, N. Gordon, J. Straszko, and S. Tamir, "Kinetics of thermal oxidation of titanium carbide and its carbon nano-composites in dry air atmosphere," Journal of Thermal Analysis and Calorimetry, vol. 88, no. 3, pp. 717-722, 2007.

[10] S. Iijima, "Helical microtubules of graphitic carbon," Nature, vol. 354 , no. 12 , pp. 56-58, 1991.

[11] M. M. J. Treacy, T. W. Ebbesen, and J. M. Gibson, "Exceptionally high Young's modulus observed for individual carbon nanotubes," Nature, vol. 381, no. 6, pp. 678-680, 1996.

[12] C. Y. Zhi, D. Y. Zhong, and E. G. Wang, "GaN-filled carbon nanotubes: synthesis and photoluminescence," Chemical Physics Letters, vol. 381, no. 5-6, pp. 715-719, 2003.

[13] P. M. Ajayan and J. M. Tour, "Materials science: nanotube composites," Nature, vol. 447, pp. 1066-1068, 2007.

[14] A. Leonhardt, M. Ritschel, D. Elefant et al., "Enhanced magnetism in Fe-filled carbon nanotubes produced by pyrolysis of ferrocene," Journal of Applied Physics, vol. 98, no. 7, Article ID 074315, 5 pages, 2005.

[15] H. Park, M. H. Kim, Y. K. Hwang, J. S. Chang, and Y. U. Kwon, "Sonochemical syntheses and catalytic properties of oxide and carbide nanocomposites on carbon nanotubes," Chemistry Letters, vol. 34, no. 2, pp. 222-223, 2005.

[16] L. Pan, T. Shoji, A. Nagataki, and Y. Nakayama, "Field emission properties of titanium carbide coated carbon nanotube arrays," Advanced Engineering Materials, vol. 9, no. 7, pp. 584587, 2007.
[17] X. Shi, H. Yang, P. Sun, G. Shao, X. Duan, and X. Zhen, "Synthesis of multi-walled carbon nanotube-tungsten carbide composites by the reduction and carbonization process," Carbon, vol. 45, no. 9, pp. 1735-1742, 2007.

[18] N. Keller, B. Pietruszka, and V. Keller, "A new one-dimensional tungsten carbide nanostructured material," Materials Letters, vol. 60, no. 13-14, pp. 1774-1777, 2006.

[19] M. Terrones, W. K. Hsu, A. Schilder et al., "Novel nanotubes and encapsulated nanowires," Applied Physics A, vol. 66, no. 3, pp. 307-317, 1998.

[20] C. N. R. Rao, R. Sen, B. C. Satishkumar, and A. Govindaraj, "Large aligned-nanotube bundles from ferrocene pyrolysis," Chemical Communications, no. 15, pp. 1525-1526, 1998.

[21] Y. Lu, Z. Zhu, and Z. Liu, "Carbon-encapsulated Fe nanoparticles from detonation-induced pyrolysis of ferrocene," Carbon, vol. 43, no. 2, pp. 369-374, 2005.

[22] J. Huo, H. Song, X. Chen, and W. Lian, "Formation and transformation of carbon-encapsulated iron carbide/iron nanorods," Carbon, vol. 44, no. 13, pp. 2849-2852, 2006.

[23] K. Jiang, C. Feng, K. Liu, and S. Fan, "A vapor-liquid-solid model for chemical vapor deposition growth of carbon nanotubes," Journal of Nanoscience and Nanotechnology, vol. 7, no. 4-5, pp. 1494-1504, 2007. 

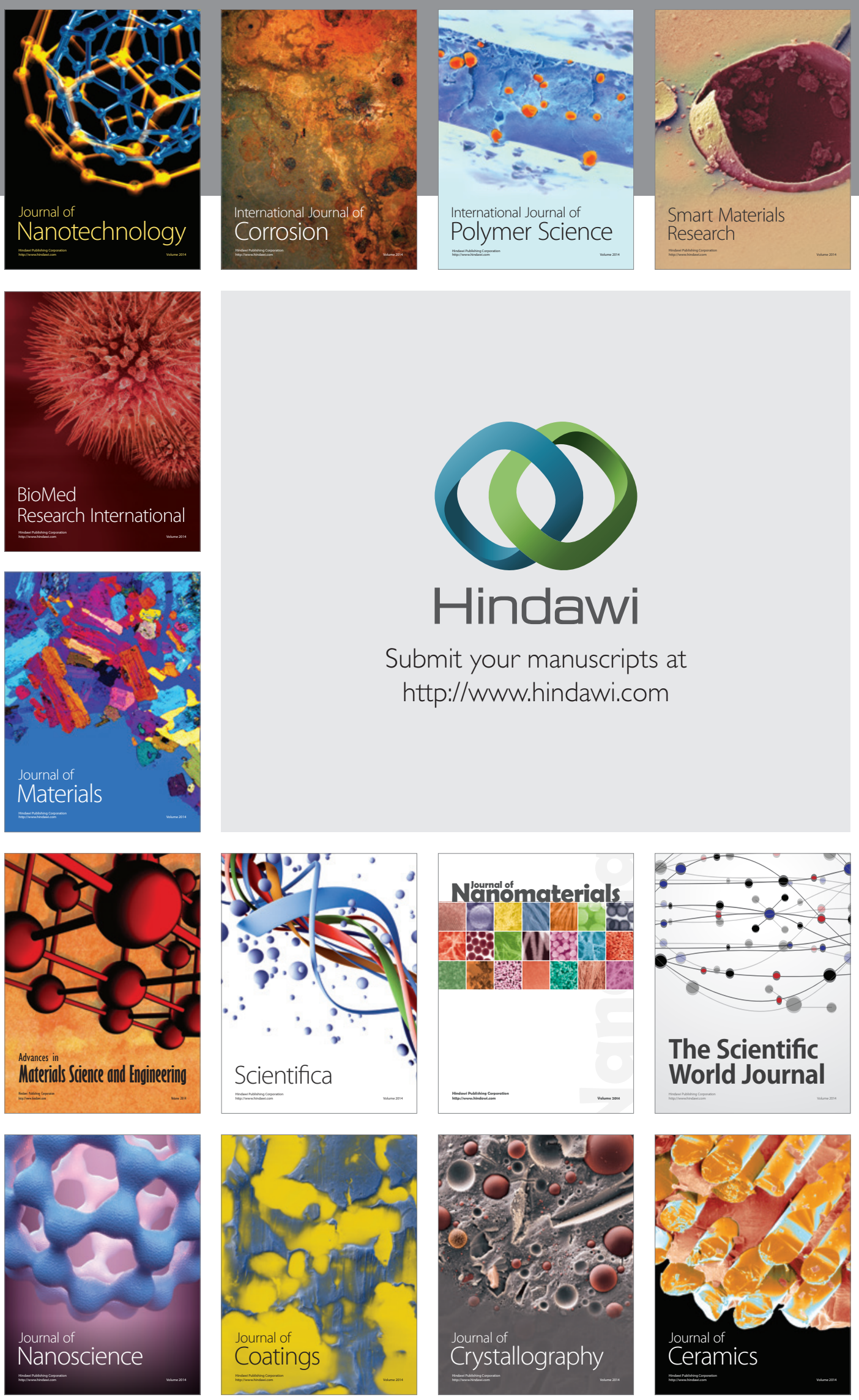

The Scientific World Journal

Submit your manuscripts at

http://www.hindawi.com

\section{World Journal}

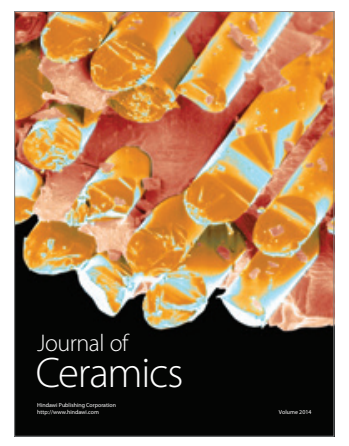

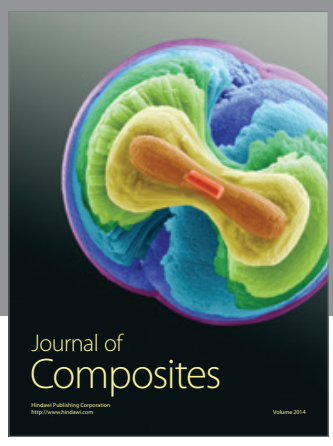
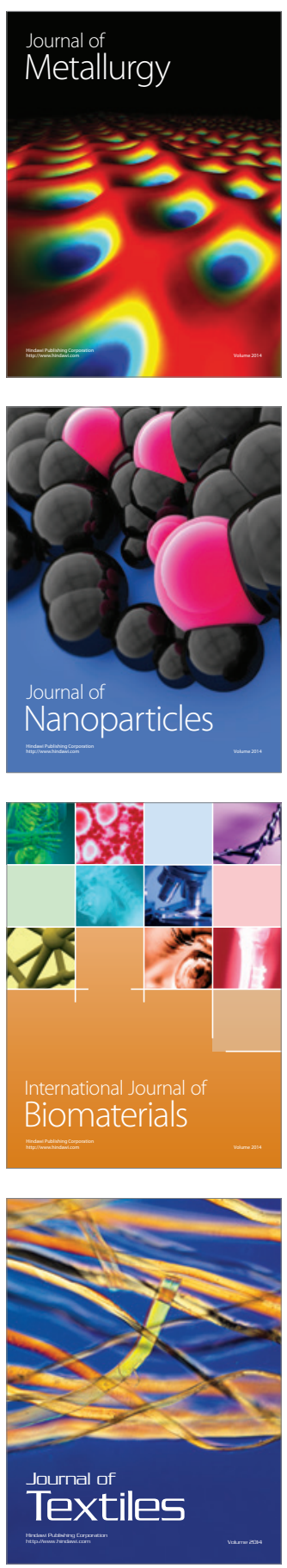